\title{
Outcome of neonates born to mothers with premature rupture of membranes
}

\author{
Ramnath Reddy ${ }^{1}, *$ Anjali Kher ${ }^{2}$ \\ Sri Lanka Journal of Child Health, 2020; 49(3): 256-262
}

\begin{abstract}
Introduction: Premature rupture of membranes (PROM) refers to rupture of fetal membranes prior to the onset of labour regardless of the gestation.

Objectives: To assess the outcome (morbidity/ mortality) of neonates born to mothers with PROM and to assess the prevalence of PROM in the Acharya Vinoba Bhave Rural Hospital (AVBRH), Sawangi (Meghe), Wardha, Maharashtra, India.
\end{abstract}

Method: This is a prospective observational study, conducted in the Department of Paediatrics, AVBRH, over a 2 year period with a sample size of 125 neonates born to mothers with history of PROM ( $\geq 8$ hours).

Results: The male to female ratio was 0.8 and the ratio of normal vaginal delivery (NVD) to lower segment caesarean section (LSCS) was 1.85 . Common associated morbidities were respiratory distress $(30.4 \%)$, clinical sepsis $(28.8 \%)$, culture positive sepsis (9.6\%), birth asphyxia (5.6\%), pneumonia $(2.4 \%)$ and meningitis $(2.4 \%)$. Neonates with blood cultures positive for coagulase negative staphylococcus and pseudomonas had 100\% mortality. Mortality rate in neonates born to mothers with a history of PROM was $2.4 \%$, sepsis and birth asphyxia being the leading causes of mortality.

Conclusions: The prevalence of PROM $\geq 8$ hours' duration in mothers of in AVBRH was $2.93 \%$. The mortality rate was $2.4 \%$, sepsis and birth asphyxia being the leading causes of mortality.

http://dx.doi.org/10.4038/sljch.v49i3.9144

${ }^{1}$ Junior Resident, ${ }^{2}$ Professor, Department of Paediatrics, Jawaharlal Nehru Medical College, Sawangi (M), Wardha, India

*Correspondence: anjalimkher@gmail.com

(iD)

orcid.org/ 0000-0003-0214-6954

(Received on 23 October 2019: Accepted after revision on 20 December 2019)

The authors declare that there are no conflicts of interest

Personal funding was used for the project.

Open Access Article published under the Creative

Commons Attribution CC-BY (cc) (i)
(Keywords: Premature rupture of membranes, early onset sepsis)

\section{Introduction}

Premature rupture of membranes (PROM) refers to rupture of fetal membranes prior to the onset of labour regardless of gestation. It is subdivided into preterm premature rupture of membranes (PPROM) which is rupture prior to 37 weeks of gestation and term premature rupture of membranes (TPROM), which is rupture after 37 weeks of gestation. Prolonged rupture of membranes is any rupture of membranes that persists for more than 24 hours and prior to the onset of labour ${ }^{1}$. PROM is one of the most common problems in obstetrics, complicating $8 \%$ to $10 \%$ of term pregnancies and approximately $1 \%$ of all preterm pregnancies ${ }^{1}$.

Current neonatal mortality rate globally is 18 per 1000 live births ${ }^{2}$. In India the neonatal mortality rate was 24 per 1000 live births ${ }^{2}$ according to UNICEF data 2015. Neonatal sepsis contributing to neonatal mortality rate is $13.6 \%{ }^{3}$. The fetal and neonatal morbidity and mortality risks are significantly affected by duration of latent period and gestation in PROM. The latent period is defined as the time from membrane rupture to onset of contractions ${ }^{1}$.The primary complication due to PROM for the mother is risk of infection and this risk increases with the duration of membrane rupture. Complications due to PROM for the newborn consists of prematurity, sepsis, fetal distress, deformation and altered pulmonary development ${ }^{4}$.

For patients with PPROM, the most likely outcome is preterm delivery within one week, with its associated morbidity and mortality risks such as respiratory distress, necrotizing enterocolitis (NEC), intra-ventricular haemorrhage and sepsis ${ }^{5}$. The association between neonatal sepsis and the duration of membrane rupture was first reported in 1963 in a study which showed a higher rate of clinical or proved sepsis in neonates born to mothers with ruptured membranes of more than 6 hours $^{6}$. In the absence of early specific and sensitive diagnostic tools for neonatal sepsis, management of infants born to mothers with PROM proves to be a dilemma, especially for asymptomatic neonates at birth ${ }^{7}$.

The predictability of laboratory investigations such as complete blood count $(\mathrm{CBC})$ and C-reactive 
protein (CRP) is low, especially at the onset of illness, or initially in asymptomatic newborns. Their use to rule out sepsis should depend on serial measurements $^{8}$. This diagnostic challenge might justify the practice of admitting all neonates born to mothers with PROM and administering empirical broad-spectrum antibiotics to these asymptomatic neonates without sepsis for prolonged period. This practice drastically increases the load on neonatal units, and exposes the newborn infants to hospitalacquired infections and medication side effects ${ }^{9}$.

\section{Objectives}

This study was undertaken to assess the outcome (morbidity/mortality) of neonates born to mothers with PROM and to assess the prevalence of PROM in the Acharya Vinoba Bhave Rural Hospital (AVBRH), Sawangi (Meghe), Wardha, Maharashtra, India.

\section{Method}

This was a prospective observational study, conducted in the Department of Paediatrics, AVBRH, Sawangi (Meghe), Wardha, Maharashtra, India, with a sample size of 125 neonates born to the mothers with history of PROM ( $\geq 8$ hours).

Inclusion criteria: All neonates born to mothers with premature rupture of membranes (PROM $>=8 \mathrm{hrs}$ ) more than or equal to eight hours and delivered in AVBRH hospital Sawangi (Meghe).

Exclusion criteria: Those who did not give consent. The data was collected in a pre-validated proforma which included age, parity, socio-economic status, maternal and obstetric history of the mother, and birth history of neonate. A thorough general examination of the neonates was done and all essential investigations were carried out.

All data were entered in the Microsoft Excel spreadsheets and Stata software (Stata 10, Stata corporation Texas, USA) was used for data analysis. Differences between means were compared by unpaired Student t-test where data was normally distributed and Mann Whitney $U$ test for nonnormally distributed data. $p$ value less than 0.05 is considered as level of significance. Distribution of data was studied by Kolmogorov Smirnov test. Quantitative data was analysed using mean, median and standard deviation. Qualitative data was summarized using percentage and proportions differences in proportion were compared by chi square test and Fischer's exact text. Differences between means were compared by unpaired Student t-test where data was normally distributed and Mann Whitney $U$ test for non-normally distributed data. To know the true positive cases, true negative cases, probability that the cases with positive CRP truly have Septicaemia, probability that the cases with negative CRP truly don't have Septicaemia and to know the potential utility of CRP respectively, for which $2 \times 2$ contingency tables were formed. Also, to know the accuracy of the CRP for septicaemia we calculated the Sensitivity, Specificity, positive predictive value, negative predictive value, Positive Likelihood ratio, and Negative Likelihood ratio for each physical sign. $\mathrm{p}$ value less than 0.05 is considered as level of significance.

Ethical clearance was obtained from the Institutional Ethics Committee of Datta Meghe Institute of Medical Sciences (Ref. No. DMIMS (DU)/IEC/ 2017-18/6695)

\section{Results}

The mean age of mothers with a history of PROM was 25 years, with a standard deviation of 2.15 years. Mean gestational age of neonates was 36.8 weeks, with a standard deviation of 2.3 weeks. Mean birth weight of neonates was $2.38 \mathrm{~kg}$, with a standard deviation of $0.54 \mathrm{~kg}$. Mean duration of PROM was 28.7 hours, with a standard deviation of 29.2 hours. In our hospital, total number of deliveries conducted during the study period was 4,261 . The prevalence of PROM in mothers of $>8$ hours duration in our hospital was $2.93 \%$. The prevalence of PROM in mothers of $>18$ hours duration in our hospital was $1.17 \%$. The incidence of culture positive early onset sepsis (EOS) attributable to PROM in this institute was $9.6 \%$. The baseline characteristics of the neonates included in the study are shown in Table 1.

Table 1: Baseline characteristics of neonates $(n=125)$

\begin{tabular}{|l|c|}
\hline \multicolumn{1}{|c|}{ Baseline characteristic } & Number (\%) \\
\hline Sex & $58(46)$ \\
Fale & $67(54)$ \\
\hline Mode of delivery & \\
Normal vaginal delivery & $82(65)$ \\
Lower segment caesarean section & $43(35)$ \\
\hline Risk factors in mother for PROM & \\
Infection to mother & \\
Previous history of PROM & $27(21.6)$ \\
Antepartum haemorrhage & $11(07.2)$ \\
Smoking & $04(03.2)$ \\
No risk factors & $02(01.6)$ \\
& $81(64.8)$ \\
\hline Birth weight of neonate & $11(07.2)$ \\
$<1.5 \mathrm{~kg}$ & $20(17.6)$ \\
$1.5-2 \mathrm{~kg}$ & $37(29.6)$ \\
$2-2.5 \mathrm{~kg}$ & $57(45.6)$ \\
$>2.5 \mathrm{~kg}$ & \\
\hline Gestational age of neonate & $05(04.1)$ \\
$<32 \mathrm{weeks}$ & $12(09.6)$ \\
$32-34$ weeks & $44(35.2)$ \\
$>34-37$ weeks & $61(48.8)$ \\
$>37-40$ weeks & $03(02.3)$ \\
$>40-42$ weeks &
\end{tabular}

PROM: Premature rupture of membranes 
Male to female ratio of the neonates was 0.87 and ratio of normal vaginal delivery (NVD) to lower segment caesarean section (LSCS) was 1.85. Most mothers belonged to the lower socio-economic class according to modified Kuppuswamy classification and there was no correlation between socioeconomic status and duration of PROM. More number of cases were low birth weight $(<2.5 \mathrm{~kg})$ neonates. It was observed that infection to mother was a major risk factor for PROM $>18$ hrs duration and previous h/o PROM was the second most common risk factor

Distribution of cases based on neonatal morbidities and duration of PROM is shown in Table 2.

Table 2: Distribution of cases based on neonatal morbidities and duration of PROM

\begin{tabular}{|c|c|c|c|c|c|c|}
\hline $\begin{array}{l}\text { Duration of } \\
\text { PROM in } \\
\text { hours } \\
(n=125)\end{array}$ & $\begin{array}{c}\text { Clinical } \\
\text { sepsis } \\
(n=36) \\
\text { No. }(\%)\end{array}$ & $\begin{array}{c}\text { Respiratory } \\
\text { distress } \\
(n=38) \\
\text { No. }(\%)\end{array}$ & $\begin{array}{c}\text { Pneumonia } \\
(n=03) \\
\text { No. }(\%)\end{array}$ & $\begin{array}{c}\text { Sepsis } \\
(n=12) \\
\text { No. }(\%)\end{array}$ & $\begin{array}{c}\text { Meningitis } \\
(\mathbf{n}=\mathbf{0 3}) \\
\text { No. }(\%)\end{array}$ & $\begin{array}{c}\text { Birth } \\
\text { asphyxia } \\
(n=7) \\
\text { No. }(\%)\end{array}$ \\
\hline $8-12$ hrs (39) & $01(02.7)$ & $02(05.2)$ & $0(0)$ & $0(0)$ & $0(0)$ & $01(14.2)$ \\
\hline$>12-18 \mathrm{hrs}(36)$ & $04(11.1)$ & $06(15.7)$ & $0(0)$ & $0(0)$ & $0(0)$ & $0(0)$ \\
\hline$>18-24 \mathrm{hrs}(11)$ & $04(11.1)$ & $05(13.1)$ & $0(0)$ & $01(08,3)$ & $0(0)$ & $01(14.2)$ \\
\hline$>24-48 \mathrm{hrs}(23)$ & $12(33.3)$ & $14(36.8)$ & $0(0)$ & $04(33.3)$ & $0(0)$ & $0(0)$ \\
\hline$>48-72 \mathrm{hrs}(08)$ & 07 (19.4) & $06(15.7)$ & $0(0)$ & $04(33.3)$ & $01(33.3)$ & $02(28.5)$ \\
\hline$>72 \mathrm{hrs}(08)$ & $08(22.2)$ & $05(13.1)$ & $03(100)$ & $03(25.0)$ & $02(66.6)$ & $03(42.8)$ \\
\hline p-value & 0.00 & 0.00 & 0.00 & 0.00 & 0.00 & 0.00 \\
\hline
\end{tabular}

Out of 125 neonates with history of PROM, 38 $(30.4 \%)$ had respiratory distress, $36(28.8 \%)$ had clinical sepsis, $12(9.6 \%)$ had culture positive sepsis, $7(5.6 \%)$ had birth asphyxia, $3(2.4 \%)$ had pneumonia and $3(2.4 \%)$ had meningitis. Respiratory distress and birth asphyxia were seen from 8-12 hours of PROM group but sepsis, pneumonia and meningitis cases were seen only $>18$ hours of PROM groups. Neonatal morbidities like clinical sepsis, respiratory distress, culture positive sepsis, meningitis, pneumonia, and birth asphyxia were commonly seen with increased duration of PROM and this is statistically significant ( $p$ value $<0.05$ ) along with percentages (Table 2 ).

Distribution of cases based on birth weight and neonatal morbidities is shown in Table 3.

Table 3: Distribution of cases based on birth weight and neonatal morbidities

\begin{tabular}{|c|c|c|c|c|c|c|c|}
\hline Weight & $\begin{array}{l}\text { No. of } \\
\text { cases } \\
(n=125)\end{array}$ & $\begin{array}{l}\text { Clinical } \\
\text { sepsis } \\
(n=36) \\
\text { No. }(\%)\end{array}$ & $\begin{array}{l}\text { Respiratory } \\
\text { distress } \\
(\mathbf{n}=\mathbf{3 8}) \\
\text { No. }(\%)\end{array}$ & $\begin{array}{l}\text { Sepsis } \\
(n=12) \\
\text { No. }(\%)\end{array}$ & $\begin{array}{l}\text { Meningitis } \\
(n=03) \\
\text { No. }(\%)\end{array}$ & $\begin{array}{l}\text { Pneumonia } \\
(\mathrm{n}=03) \\
\text { No. }(\%)\end{array}$ & $\begin{array}{l}\text { Birth } \\
\text { asphyxia } \\
(n=07) \\
\text { No. }(\%)\end{array}$ \\
\hline$\leq 1.5 \mathrm{~kg}$ & 11 & 07 (19.4) & $07(18.4)$ & $05(41.6)$ & $01(33.3)$ & $0(0)$ & $01(14.2)$ \\
\hline$>1.5-2 \mathrm{~kg}$ & 20 & $09(25.0)$ & $12(31.5)$ & $01(08.3)$ & $0(0)$ & $02(66.7)$ & $0(0)$ \\
\hline$>2-2.5 \mathrm{~kg}$ & 37 & $11(30.5)$ & $09(23.6)$ & $03(25.0)$ & $01(33.3)$ & $01(33.3)$ & $03(42.9)$ \\
\hline$>2.5 \mathrm{~kg}$ & 57 & $09(25.0)$ & $10(26.3)$ & $03(25.0)$ & $01(33.3)$ & $0(0)$ & $03(42.9)$ \\
\hline p-value & & 0.003 & 0.000 & 0.000 & 0.439 & 0.085 & 0.595 \\
\hline
\end{tabular}

It was seen that extremely low birth weight babies were more prone to respiratory distress, clinical sepsis and culture positive sepsis. There is statistical significance between neonates with low birth weight and neonatal morbidities like respiratory distress, clinical sepsis and culture proven sepsis ("p" value $<0.05$ and based on percentages) (Table 3 ).

Distribution of cases based on gestational age and neonatal morbidities is shown in Table 4. 
Table 4: Distribution of cases based on gestational age and neonatal morbidities

\begin{tabular}{|c|c|c|c|c|c|c|c|}
\hline $\begin{array}{l}\text { Gestational } \\
\text { age }\end{array}$ & $\begin{array}{l}\text { No. of } \\
\text { cases } \\
(n=125)\end{array}$ & $\begin{array}{l}\text { Clinical } \\
\text { sepsis } \\
(n=36) \\
\text { No. }(\%) \\
\end{array}$ & $\begin{array}{l}\begin{array}{l}\text { Respiratory } \\
\text { distress } \\
(n=38) \\
\text { No. }(\%)\end{array} \\
\end{array}$ & $\begin{array}{l}\text { Sepsis } \\
(n=12) \\
\text { No. }(\%)\end{array}$ & $\begin{array}{l}\text { Meningitis } \\
(\mathrm{n}=03) \\
\text { No. }(\%)\end{array}$ & $\begin{array}{l}\text { Pneumonia } \\
(\mathrm{n}=03) \\
\text { No. }(\%)\end{array}$ & $\begin{array}{l}\text { Birth } \\
\text { asphyxia } \\
(n=07) \\
\text { No. }(\%) \\
\end{array}$ \\
\hline$\leq 32 \mathrm{wks}$ & 05 & $03(08.3)$ & $03(07.8)$ & $02(16.6)$ & $0(0)$ & $0(0)$ & $0(0)$ \\
\hline $32.1-34$ wks & 12 & $09(25.0)$ & 09 (23.6) & $03(25.0)$ & $0(0)$ & $02(66.7)$ & $0(0)$ \\
\hline $34.1-37$ wks & 44 & $12(33.3)$ & $12(31.5)$ & $04(33.3)$ & $02(66.7)$ & $0(0)$ & $02(28.5)$ \\
\hline $37.1-40 \mathrm{wks}$ & 61 & $12(33.3)$ & $13(34.2)$ & $03(25.0)$ & $01(33.3)$ & $01(33.3)$ & $05(71.4)$ \\
\hline$>40 \mathrm{wks}$ & 03 & $0(0)$ & $01(02.6)$ & $0(0)$ & $0(0)$ & $0(0)$ & $0(0)$ \\
\hline p-value & & 0.000 & 0.001 & 0.045 & 0.849 & 0.027 & 0.666 \\
\hline
\end{tabular}

Of the preterm babies in this study, $39.3 \%$ were having clinical sepsis, $39.3 \%$ were having respiratory distress and $14.7 \%$ were having culture proven sepsis. Premature babies born to mothers with a history of PROM were more prone to neonatal morbidities like respiratory distress, clinical and culture proven sepsis and pneumonia. Infection to mother is the most important risk factor leading to morbidities like clinical sepsis, culture positive sepsis, meningitis, respiratory distress, birth asphyxia in neonates born to mothers with a history of PROM (Table 4).

Distribution of cases based on prophylactic prenatal antibiotics received by mothers with a history of PROM to neonates with clinical and culture proven sepsis is shown in Table 5.

Table 5: Distribution of cases based on prophylactic prenatal antibiotics received by mothers with h/o PROM to neonates with clinical and culture proven sepsis

\begin{tabular}{|l|c|c|c|}
\hline \multicolumn{1}{|c|}{ Prenatal antibiotics } & No. of mothers $(\boldsymbol{n}=\mathbf{1 2 5})$ & $\begin{array}{c}\text { Clinical sepsis }(\boldsymbol{n}=\mathbf{3 6}) \\
\text { No. (\%) }\end{array}$ & $\begin{array}{c}\text { Culture positive sepsis } \\
(\boldsymbol{n}=\mathbf{1 2}) \\
\text { No. }(\mathbf{\%})\end{array}$ \\
\hline Not received & 52 & $26(72.2)$ & $08(66.7)$ \\
\hline Received & 73 & $10(27.8)$ & $04(33.3)$ \\
\hline p-value & & $\mathbf{0 . 0 0}$ & 0.064 \\
\hline
\end{tabular}

Out of 125 mothers with a history of PROM, 73 $(58.4 \%)$ had received prenatal antibiotics and 52 $(41.6 \%)$ had not received antibiotics. Prenatal prophylactic antibiotics to the mothers with PROM have reduced the incidence of clinical sepsis in neonates, but there was no significant correlation between prenatal prophylactic antibiotics and culture positive sepsis (Table 5).

Distribution of cases based on outcome in relation to clinical sepsis, culture positive sepsis and birth asphyxia is shown in Table 6.

Table 6: Distribution of cases based on outcome in relation to clinical sepsis, culture positive sepsis and birth asphyxia

\begin{tabular}{|l|c|c|c|c|c|}
\hline \multicolumn{1}{|c|}{ Outcome } & $\begin{array}{c}\text { No. of cases } \\
(\mathbf{n = 1 2 5}) \\
\text { No. }(\%)\end{array}$ & $\begin{array}{c}\text { Clinical sepsis } \\
(\mathbf{n = 3 6 )} \\
\text { No. }(\%)\end{array}$ & $\begin{array}{c}\text { Respiratory } \\
\text { distress } \\
(\mathbf{n = 3 8}) \\
\text { No. }(\%)\end{array}$ & $\begin{array}{c}\text { Sepsis } \\
(\mathbf{n = 1 2}) \\
\text { No. (\%) }\end{array}$ & $\begin{array}{c}\text { Birth asphyxia } \\
(\mathbf{n}=\mathbf{0 7}) \\
\text { No. }(\%)\end{array}$ \\
\hline Alive & $122(97.6)$ & $33(91.6)$ & $37(97.4)$ & $10(83.3)$ & $06(85.7)$ \\
\hline Dead & $03(02.4)$ & $03(08.3)$ & $01(02.6)$ & $02(16.6)$ & $01(14.2)$ \\
\hline p-value & & 0.06 & 0.911 & $\mathbf{0 . 0 1}$ & $\mathbf{0 . 0 3 4}$ \\
\hline
\end{tabular}

Blood culture positive sepsis was seen in 12 neonates. Out of them coagulase negative staphylococcus and pseudomonas attributed to mortality whereas most common organism grown was methicillin resistant staphylococcus aureus (MRSA). The mortality rate was $2.4 \%$, with sepsis and birth asphyxia being the leading causes of mortality (Table 6)

\section{Discussion}

The incidence of PROM $>8$ hours duration in AVBRH was $2.93 \%$. Most studies have included neonates born to mothers with PROM $>18$ hours duration, but we have included neonates with PROM $>8$ hours duration because we wanted to find out the incidence of early onset sepsis in these neonates also. The incidence of PROM $>18 \mathrm{hrs}$ duration in mothers in our hospital was $1.17 \%$. This was similar to the incidence rate of $1.3 \%$ in a study by Idrisia $e t$ 
$a l^{11}$, but lower than the $2.7 \%$ incidence rate in the study by Alam et $a l^{17}$, and the $4.2 \%$ incidence rate in the study by Sharma et $a l^{13}$.

In this study, $70 \%$ cases were in the lower socioeconomic class and $30 \%$ were in the lower middle socio-economic class. This is consistent with the study by Amulya $\mathrm{N}$ et al $^{10}$ in which $80 \%$ of cases belonged to low socioeconomic status, $13.3 \%$ belonged to middle socioeconomic status and $6.7 \%$ belonged to higher socioeconomic status. Similar results were seen in a study by Idrisia et $a l^{11}$ where $79.5 \%$ were lower socioeconomic class cases and in in a study by Chhangetae et $a l^{12}$ where $54 \%$ were lower socioeconomic class cases. However, in a study by Sharma et $a l^{13} 56.9 \%$ were middle socioeconomic class cases, which is contrary to our findings. It is observed in present study that PROM was high in cases of low socioeconomic status (70\%) which might be due to poor nutritional status, anaemia and increased genitourinary infections due to poor personal hygiene.

In this study out of 125 neonates born to PROM mothers, $61(48.8 \%)$ were preterm and $64(51.2 \%)$ were term. Similar results were seen in a study by Al- Qaqa et al ${ }^{14}$ where $38 \%$ were term and $62 \%$ were preterm, and in a study by Ocviyanti et $a l^{15}$ where $54.1 \%$ were preterm and $45.9 \%$ were term neonates. Contrary findings were seen in a study by Ramesh $\mathrm{TV}$ et $a l^{16}$ where term neonates were $62 \%$, and in a study by Alam et $\mathrm{al}^{17}$ where term neonates were $72 \%$.

In this study $30.4 \%$ neonates had respiratory distress, $2.4 \%$ had pneumonia, $9.6 \%$ had culture proven sepsis, $2.4 \%$ had meningitis and $5.6 \%$ had birth asphyxia. Similar results were seen in a study by Thayi et al ${ }^{18}$ where $16.5 \%$ neonates had respiratory distress and $11.1 \%$ had sepsis, in a study by Patil et al where $26 \%$ neonates had respiratory distress, $14 \%$ has sepsis, $4 \%$ had interventricular haemorrhage and contrary finding were seen in a study by Chaangte et $a l^{12}$ where $2 \%$ had sepsis, $2 \%$ had birth asphyxia and 1\% had respiratory distress and this could be attributed to only term neonates being included in their study.

When the duration of PROM was $<24$ hours, $15.1 \%$ neonates had respiratory distress in our study compared to $37.5 \%$ in the study by Lokhande et $a l^{19}$, $37.5 \%$ in the study by Ramesh TV et al ${ }^{16}$ and $28.6 \%$ in the study by Patil et $a l^{20}$. When the duration of PROM was 24-72 hours, 64\% neonates had respiratory distress in our study compared to $13 \%$ in the study by Lokhande et $a l^{19}, 18.5 \%$ in the study by Ramesh TV et al ${ }^{16}$ and $20 \%$ in the study by Patil et $a l^{20}$. When the duration of PROM was $>72$ hours, $62.5 \%$ neonates had respiratory distress in our study compared to $20 \%$ in the study by Lokhande et $a l^{19}$, $63.1 \%$ in the study by Ramesh TV et $\mathrm{al}^{16}$ and $16.6 \%$ in the study by Patil et $a l^{20}$. Thus in our study and that of Ramesh TV et $\mathrm{al}^{16}$, as the duration of PROM increased the respiratory distress increased.

When the duration of PROM was $<24$ hours, sepsis was seen in $1.16 \%$ cases in our study compared to $9.8 \%$ in the study by Patil et $a l^{20}$ and no sepsis in studies by Lokhande et $a l^{19}$ and Ramesh TV et $\mathrm{al}^{16}$. When the duration of PROM was 24-72 hours, sepsis was seen in $25 \%$ in our study compared to $18.5 \%$ in the study by Ramesh TV et $\mathrm{al}^{16}, 20 \%$ in the study by Patil et $a l^{20}$ and no sepsis in the study by Lokhande $e t a l^{19}$. When the duration of PROM was $>72$ hours, sepsis was seen in $37.5 \%$ cases in our study compared to $40 \%$ in the study by Lokhande $e t$ $a l^{19}, 15.7 \%$ in the study by Ramesh TV et $\mathrm{al}^{16}$ and $33.3 \%$ in the study by Patil et $a l^{20}$. As the duration of PROM increased the incidence of sepsis increased in all the above studies. In this study $2.4 \%$ neonates had meningitis and $2.4 \%$ had pneumonia and these findings were similar to a study by Lokhande et $a l^{19}$ in which $1.7 \%$ neonates had meningitis and $1.7 \%$ had pneumonia.

In this study, $28.8 \%$ had clinical sepsis and $9.6 \%$ had culture-positive sepsis, similar results were found in a study conducted by Thayi S et $a l^{18}$ where clinical sepsis was observed in $30 \%$ of cases and culturepositive sepsis was observed in $11 \%$ of neonates. In a study by Nili et $a l^{4}$ clinical sepsis was observed in $20.2 \%$ of cases and culture-positive sepsis was observed in $5.5 \%$ of cases. These lower numbers could be attributed to selection criteria of cases, they have included duration of PROM from 1 hour.

In this study total mortality was $2.4 \%$, and the most common causes leading to death were sepsis and birth asphyxia. A study by Lokhande et $a l^{19}$ had a mortality of $1.7 \%$ and a study by Mohan S, et $a l^{21}$ had a mortality of $2.9 \%$ which are similar to the mortality in our study. However, the mortality was $5 \%$ in studies by Sharma et $a l^{13}$ and Ramesh TV et $a l^{16}$ which could be attributed to the inclusion criteria as they have included neonates whose mother had a history of PROM for more than 18 hours. In the study by Poovathi et $\mathrm{al}^{22}$ the mortality was $10 \%$ and this could be due to the inclusion of only preterm neonates in their study.

\section{Conclusions}

The prevalence of $\mathrm{PROM} \geq 8$ hours' duration in mothers delivered in AVBRH was $2.93 \%$ and in $>18$ hours duration of PROM it was $1.17 \%$. Neonatal morbidities like clinical sepsis, respiratory distress, culture-positive sepsis, meningitis, pneumonia, and birth asphyxia increased as the duration of PROM 
increased. The mortality rate was $2.4 \%$, sepsis and birth asphyxia being the leading causes of mortality.

\section{References}

1. Scott JR, Gibbs RS, Karlan BY, Haney AF, Danforth DN, editors. Danforth's Obstetrics and Gynecology, 9th ed. Lippincott Williams \& Wilkins; 2003.

2. Mortality rate, neonatal (per 1,000 live births). Available from:

https://data.worldbank.org/indicator/SH.D YN.NMRT

3. Maternal and Newborn Health Disparities country profiles. November 2016. Available from: https://ata.unicef.org/resources/maternalnewborn-health-disparities-countryprofiles/

4. Nili F, Ansari S. Neonatal complications of premature rupture of membranes. Acta Medica Iranica 2003; 41(3):175-9.

5. Beydoun SN, Yasin SY. Premature rupture of the membranes before 28 weeks: conservative management. American Journal of Obstetrics and Gynecology 1986; 155(3): 471-9. https://doi.org/10.1016/00029378(86)9025 $7-7$

6. Calkins LA. Premature spontaneous rupture of the membranes. American Journal of Obstetrics and Gynecology 1952; 64(4):871-7. https://doi.org/10.1016/S00029378(16)388 01-9

7. Marlowe SE, Greenwald J, Anwar M, Hiatt M, Hegyi T. Prolonged rupture of membranes in the term newborn. American Journal of Perinatology 1997; 14(8):4836.

https://doi.org/10.1055/s-2007-994185

PMid: 9376011

8. Nuntnarumit P, Pinkaew O, Kitiwanwanich S. Predictive values of serial C-reactive protein in neonatal sepsis. Journal of the Medical Association of Thailand. 2002; 85 Suppl 4:S1151-8.

9. Carola D, Vasconcellos M, Sloane A, McElwee D, Edwards C, Greenspan J, et al.
Utility of early-onset sepsis risk calculator for neonates born to mothers with chorioamnionitis. Journal of Pediatrics 2018; 195:48-52.e41. https://doi.org/10.1016/j.jpeds.2017.11.04 5 PMid: 29275925

10. Amulya MN. Ashwini MS. Maternal outcome in term premature rupture of membranes. International Journal of Reproduction, Contraception, Obstetrics and Gynecology 2019; 8(2):576-9. https://doi.org/10.18203/23201770.ijrcog2 0190287

11. Idrisa A, Pius S, Bukar M. Maternal and neonatal outcomes in premature rupture of membranes at University of Maiduguri Teaching Hospital, Maiduguri, NorthEastern Nigeria. Tropical Journal of Obstetrics and Gynaecology 2019; 36(1):15-20. https://doi.org/10.4103/TJOG.TJOG_89_1 8

12. Chhangte Z, Vaz A, Singh MR, Singh CS. Fetomaternal outcome of term pregnancy with premature rupture of membranes. IOSR Journal of Dental and Medical Sciences 2018; 17(4):31-41.

13. Sharma SK, Dey M. Maternal and neonatal outcome in cases of premature rupture of membranes beyond 34 weeks of gestation International Journal of Reproduction, Contraception, Obstetrics and Gynecology 2017; 6(4):1302. https://doi.org/10.18203/23201770.ijrcog2 0171382

14. Al-Qa'Qa' K, Al-Awaysheh F. Neonatal outcome and prenatal antibiotic treatment in premature rupture of membranes. Pakistan Journal of Medical Sciences 2005; 21(4):441-4.

15. Ocviyanti D, Wahono WT. Risk factors for neonatal sepsis in pregnant women with premature rupture of the membrane. Journal of Pregnancy 2018; 2018: Article ID 4823404.

https://doi.org/10.1155/2018/4823404

PMid: 30402288 PMCid: PMC6191960

16. Ramesh TV, Panigrahi B, Pranaya P, Bindu $\mathrm{PH}$. Outcome of neonates born to mothers with premature rupture of membranes. 
International Journal of Contemporary Pediatrics 2018; 5(4):1190-4. https://doi.org/10.18203/23493291.ijcp201 81994

17. Alam MM, Saleem AF, Shaikh AS, Munir O, Qadir M. Neonatal sepsis following prolonged rupture of membranes in a tertiary care hospital in Karachi, Pakistan. Journal of Infection in Developing Countries 2014; 8(1):67-73.

https://doi.org/10.3855/jidc.3136

PMid: 24423714

18. Thayi S, Paramahamsa R. Outcome of newborns born to mothers with prolonged rupture of membrane. Paediatric Review: International Journal of Pediatric Research 2016; 3(11).

19. Lokhande $\mathrm{S}$, Nistane $\mathrm{R}$. Incidence of morbidity and mortality in neonate born to mothers with premature rupture of membranes. International Journal of Contemporary Pediatrics 2016; 3(4):1394-400.

https://doi.org/10.18203/23493291.ijcp201 63685
20. Patil S, Patil V. Maternal and foetal outcome in premature rupture of membranes. IOSR Journal of Dental and Medical Sciences 2014; 13(12): 56-83. https://doi.org/10.9790/0853-131275683

21. Mohan SS, Thippeveeranna C, Singh NN, Singh LR. Analysis of risk factors, maternal and fetal outcome of spontaneous preterm premature rupture of membranes: a cross sectional study. International Journal of Reproduction, Contraception, Obstetrics and Gynecology 2017; 6(9):3781. https://doi.org/10.18203/23201770.ijrcog2 0173623

22. M. P, Yogalaksmi Y. A study of perinatal outcome in preterm premature rupture of membranes. International Journal of Reproduction, Contraception, Obstetrics and Gynecology 2018; 7(12):5061. https://doi.org/10.18203/23201770.ijrcog2 018496 